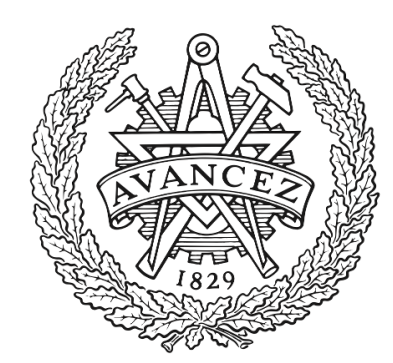

\title{
CHALMERS
}

UNIVERSITY OF TECHNOLOGY

\section{Integration Aspects of Full Converter Wind Turbines and the Impact on Long-term Voltage Stability}

Downloaded from: https://research.chalmers.se, 2023-04-26 07:40 UTC

Citation for the original published paper (version of record):

Hagmar, H., Le, A., Carlson, O. et al (2019). Integration Aspects of Full Converter Wind Turbines and the Impact on Long-term Voltage Stability. IEEE Power and Energy Society General Meeting. http://dx.doi.org/10.1109/PESGM40551.2019.8973939

N.B. When citing this work, cite the original published paper. 


\section{Integration Aspects of Full Converter Wind Turbines and the Impact on Long-term Voltage Stability}

\author{
Hannes Hagmar, Le Anh Tuan, Ola Carlson \\ Department of Electrical Engineering \\ Chalmers University of Technology \\ Gothenburg, Sweden \\ hannes.hagmar@chalmers.se
}

\author{
Robert Eriksson \\ Market and System Development \\ Svenska Kraftnät \\ Sundbyberg, Sweden \\ robert.eriksson@svk.se
}

\begin{abstract}
This paper examines how various integration aspects of full converter wind turbines, such as grid code design, control aspects, and placement of turbines, impact the long-term voltage stability of a power system. The simulations are conducted on a modified version of the Nordic32 test system. Different cases have been analyzed and show, for example, that if over-dimensioning of converters is implemented, it is mainly the converters' current capacity that should be increased since the voltage limitation of converters seldom is reached during voltage instability events. Furthermore, a restrictive reactive control scheme is tested, with the aim of minimizing the wear and maintenance of converter components. Although found to generally reduce the voltage stability, the proposed control scheme could be adopted during specific conditions where the local need of voltage support is low. The placement of larger wind farms was found to have the largest impact, both on long-term voltage stability of the system itself, and on the effect that the analyzed design and control aspects had on the system stability. Consequently, the placement of WFs is found be an important factor to consider when designing ancillary services and grid codes for wind power.
\end{abstract}

Index Terms-Long-term voltage stability, full converter wind power, integration aspects, grid codes, power control schemes

\section{INTRODUCTION}

During the last decades, the global wind power market has been the fastest growing energy generation sector in the world [1]. The impact of wind power on long-term voltage stability (LTVS) is becoming an increasingly important topic [2], and in response to these challenges, a range of actions have been proposed in the research and by the industry. The technical requirements, or grid codes, for connecting wind farms (WFs) have been updated and strengthened in several countries in the world [3], [4]. Stricter requirements have led to an increasing adoption of full converter based WFs (FC-WFs) in power systems, mainly due to their flexibility in controlling the output and response of the turbine [5].

The maximum capacity of wind power in a power system is affected by numerous aspects, such as the placement of turbines, control schemes, reactive power support capability, and the availability of reserve power generation. Aspects of wind power generation, ranging from grid integration issues [2], [6], [7], control aspects [8], [9], or possibilities of providing ancillary services [5], [10], have been examined in previous papers. A focus in these previous papers has also been to examine how WFs can be designed to better contribute to the LTVS. However, designing a system that better contributes to the system stability often comes with a cost, be it increased cost for sizing of converters, or increased wear of converters due to increased reactive power support.

The main objective of this paper is to bring new insights in how different integration aspects of FC-WFs affect the LTVS of a power system. Examined design aspects include grid code design, power control aspects, and placement and output of larger FC-WFs. The results are also put into context with economic aspects of, for example, designing grid codes or choosing control schemes for larger WFs. More specifically, the aim of the paper is to determine when and during what conditions certain design or control aspects are the most important, both with respect to technical and economic aspects.

\section{FC-WF POWER GENERATION Aspects}

\section{A. Modeling of equivalent circuit of WFs}

A wind farm consisting of several wind turbines can in power flow studies be simplified into a single equivalent unit, as illustrated in Fig. 1. The impedance of wind farm feeders, filters, collectors, and step-up transformers may then be transformed into an equivalent impedance of a grid connected stepup transformer [5]. The active and reactive power capability of FC-WFs can then be derived from this equivalent circuit.

The grid converter voltage $\left(V_{c}\right)$ is controlled by alterations of the modulation index, while the the phase angle $(\delta)$ is controlled by changing the switching pattern of the converters. The maximum value of $V_{c}$ is a design value determined by the size and ratings of the wind turbine converters, and it is an important factor for dimensioning components to meet different grid codes and requirements [5].

\section{B. Modeling active and reactive power capability}

A FC-WF can provide reactive power independently as long as it is operating within the converter limits, while active power output is determined by the actual mechanical power generated by the turbine. The maximum current capability of a converter can be represented by a circle in the $P Q$-plane, given by [5]:

$$
P^{2}+Q^{2}=\left(V_{g} I_{c}\right)^{2}
$$




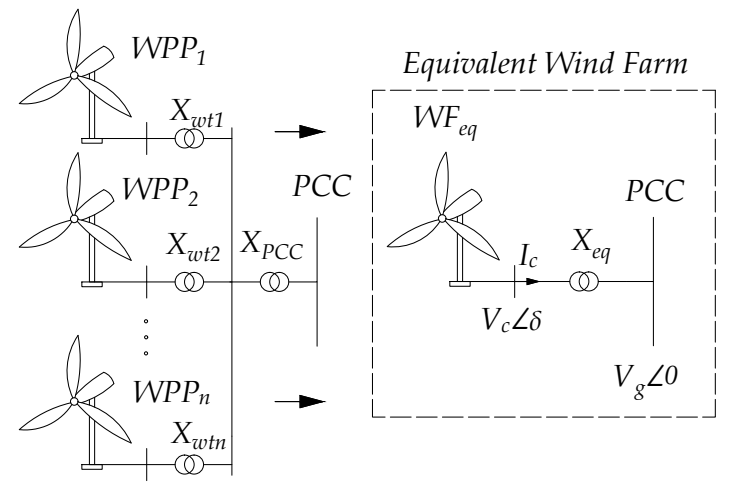

Fig. 1. Equivalent circuit diagram of a wind farm

where $P$ and $Q$ represent the active and reactive power production at the AC grid connection point, and $V_{g}$ and $I_{c}$ represent the grid voltage and converter current, respectively. Another limit is constituted by the maximum voltage across the converter transistors, and consequently the difference between the grid converter voltage $\left(V_{c}\right)$ and the grid voltage $\left(V_{g}\right)$. The relationship between $P$ and $Q$ at the converter limit is given by [5]:

$$
P^{2}+\left(Q+\frac{V_{g}^{2}}{X_{e q}}\right)^{2}=\left(\frac{V_{c} V_{g}}{X_{e q}}\right)^{2}
$$

where $X_{e q}$ is the total equivalent reactance of the wind farm. The maximum values of the converter current and voltage $\left(V_{c, \max }\right.$ and $\left.I_{c, \max }\right)$ are determined by the ratings of the grid connected converters. The converter current is highest when active and reactive power are at rated values $\left(P_{r}\right.$ and $\left.Q_{r}\right)$, while the grid voltage is at the minimum. This relationship, given in p.u. by simplifying the right-hand side by taking $P_{R}$ and $Q_{R}$ as the MVA base of the system, is given by:

$$
I_{c, \max }=\frac{\sqrt{P_{r}^{2}+Q_{r}^{2}}}{V_{g, \min }}=\frac{\sqrt{1+\tan ^{2} \theta_{R}}}{V_{g, \min }}
$$

where $\theta_{R}$ is the rated power factor angle of the converter. The maximum required converter voltage can be derived using (2) and it is highest when the grid voltage and the system frequency are at the maximum level, and the active and reactive power of the WF are at rated values. This relationship in p.u. is given by [5]:

$$
V_{c, \max }=\frac{f_{\max } X_{e q}}{V_{g, \max }} \sqrt{1+\left(\tan \theta_{r}+\frac{V_{g, \max }^{2}}{f_{\max } X_{e q}}\right)^{2}}
$$

where $f_{\max }$ and $V_{g, \max }$ are the maximum frequency and grid voltage, respectively.

\section{SimUlATION APPROACH AND DESIGN}

\section{A. Simulation aspects}

Several scenarios are simulated, such as varying levels of wind generation, power control approaches, and design aspects

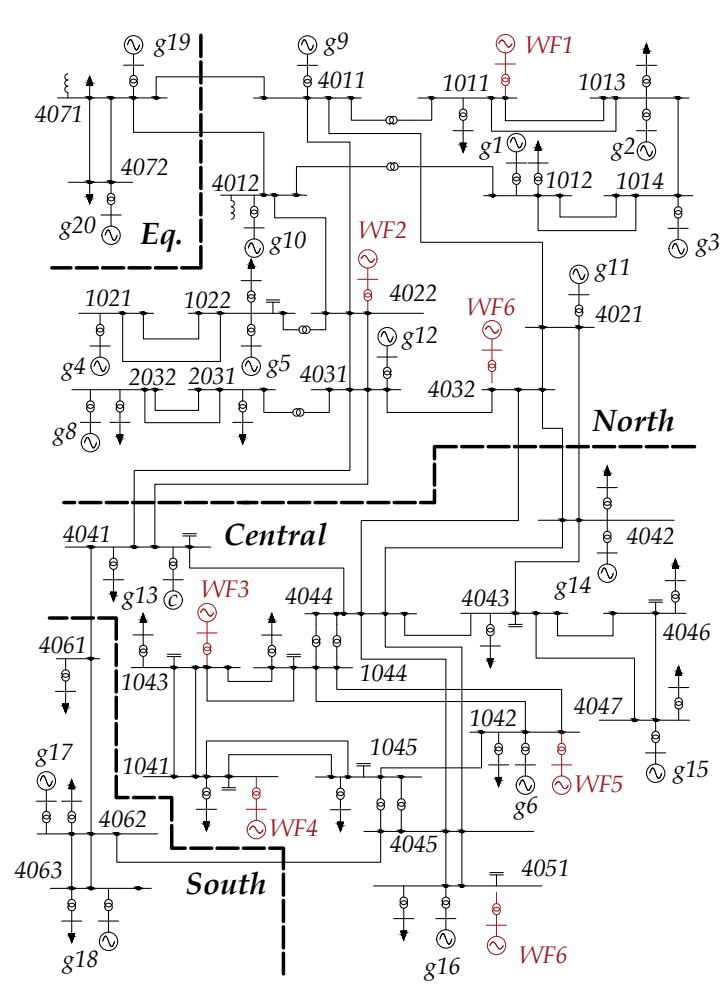

Fig. 2. The modified Nordic32 Test System with inclusion of 6 separate WFs

of grid codes. The simulations are based on a modified version of the Nordic32 test system presented in [11], and the singleline diagram is found in Fig. 2. The following simulations are all based on the unstable version of the system, denoted as the "Operating point $\mathrm{A}$ " in the Nordic32 test system and all required parameters can be found in [11]. All the simulations are performed in $\mathrm{PSS} \circledast \mathrm{E}$ version 34.2.0 with its built-in dynamical models [12].

1) WF placement and generation: To simulate a future power system with a higher penetration of WFs, six separate systems (WF1-WF6) have been included into the test system. The placement of the largest system, WF6, is varied in the simulations, and two different cases are examined. The first case is when WF6 is placed in the area denoted as "Central" (bus 4051), and the second when WF6 is placed in the area denoted as "North" (bus 4032), see Fig. 2. Furthermore, the output of the WFs is varied in the simulations, and two cases are examined: a very high wind case when all WFs generate $95 \%$ of rated $P$, and a lower wind case when all WFs operates at $40 \%$ of rated $P$.

2) Grid code design: In 2016, the European Union (EU) adopted new regulations regarding connection of powergenerator modules such as larger WFs [3]. The regulations state the requirements of providing reactive power while operating at rated capacity and at various levels of grid voltage. The regulations state the maximum reactive power requirements for WF owners, with reactive power requirements as a function between grid voltage and $Q / P_{M A X}$-ratio. The final specific design of the grid codes and the requirements are left to be 
decided each country's legislative body. From a societal view, they should be designed both with respect to grid requirements of stability and to economic aspects for the WF owner.

In the simulations, three proposed grid code designs are examined where the capability to provide reactive power under certain operating points are varied. The three grid code designs are illustrated in Fig. 3.

(i) Grid Code 1: Illustrated in Fig. 3 as the red dotted square, the same reactive power requirement is used for any values of grid voltage. This is a stricter grid code, requiring higher capacity of converters to be able to produce reactive power at all operating points.

(ii) Grid Code 2: Illustrated in Fig. 3 as a black step-wise increasing/decreasing function, the adaptive reactive power requirements are reduced step-wise as the grid voltage increases. The adaptive grid code reduces the need of over-dimensioning converters, although not being able to generate as much reactive power during all conditions.

(ii) Grid Code 3: Illustrated in Fig. 3 as the green dashed square, an even less strict grid code is adapted, requiring only $0.15 Q / P_{\max }$ at 1 p.u. grid voltage.

3) Voltage control approach: The failure mechanisms of power electronic devices are complex and affected by numerous factors, where thermal cycling is one of the most critical failure causes [13]. The life-time of IGBTs in a FC-WF may be affected both during stable operation and during varying conditions caused by, for example, wind gusts or varying reactive power demand. Higher average operating currents increase the junction temperatures, which in turn make the IGBTs more sensitive to thermal cycling damage [14].

In response to this, two different strategies for voltage control of the FC-WFs are simulated. The first one (in coming simulations denoted as $\left.V_{\text {ctrld }}\right)$ is the same as for regular synchronous generators, where the FC-WFs always participate in controlling the voltage to the scheduled level. In the second control strategy (in coming simulations denoted as $V_{\text {reserv }}$ ), the FC-WFs only participate in voltage control when the grid voltage $\left(V_{g}\right)$ is equal or less than 0.95 p.u. Thus, in stable conditions, the reactive power is controlled to be minimized. However, as soon as $\left(V_{g}\right)$ drops below 0.95 p.u., the reactive power generation is increased to control the voltage back to 0.95 p.u. The benefits of such an approach would be less thermal stress and conduction losses of the converter IGBTs. However, the grid would be less stiff and the the voltage stability could suffer.

\section{B. System stress level, disturbances, and stability criterion}

For all combinations of the design aspects described in the previous section, the system is stressed until a stability criterion is violated. The stability criterion used in the simulations is that the post-contingency state is considered stable if, over a simulation interval of 600 seconds, all distribution bus voltages are restored above 0.95 p.u. The highest system stress level is then found by gradually increasing all the loads in the system and applying a contingency that further stresses the system.

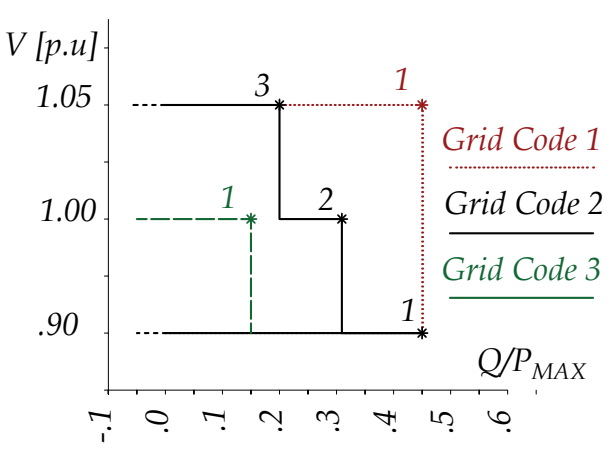

Fig. 3. Three different grid code designs to be tested in simulations

TABLE I

DATA OF ADDED WFS

\begin{tabular}{|c|c|c|c|c|c|c|}
\hline Name & Bus & Replaces & $\begin{array}{l}\text { Base voltage } \\
(\mathrm{kV})\end{array}$ & $\begin{array}{l}X_{e q} \\
(\mathrm{pu})\end{array}$ & $\begin{array}{l}P_{\max } \\
(\mathrm{MW})\end{array}$ & $\begin{array}{l}V_{\text {sched }} \\
\text { (pu) }\end{array}$ \\
\hline WF1 & 1011 & - & 33.0 & 0.3 & 220 & 1.0520 \\
\hline WF2 & 4022 & - & 33.0 & 0.3 & 200 & 1.0170 \\
\hline WF3 & 1043 & g7 & 33.0 & 0.3 & 180 & 1.0141 \\
\hline WF4 & 1041 & - & 33.0 & 0.3 & 110 & 1.0141 \\
\hline WF5 & 1042 & - & 33.0 & 0.3 & 110 & 1.0141 \\
\hline \multirow[t]{2}{*}{ WF6 } & 4051 & - & 33.0 & 0.3 & 500 & 1.0531 \\
\hline & & & or & & & \\
\hline WF6 & 4032 & - & 33.0 & 0.3 & 500 & 1.0531 \\
\hline
\end{tabular}

For each of the gradually increasing load levels, different types of contingencies are tested, as different design aspects will cause the system to be sensitive to different faults. To reduce the number of simulations, only tripping of transmission lines that connect either of the different regions (excluding the "Equivalent" region) is tested.

\section{Simulation parameters}

All WFs are simulated generically using the built-in models WT4G2 and WT4E2 in PSS®E. The parameters for the dynamic models are gathered from [12], with reference to a Siemens 2.3 MW wind turbine. The total $X_{e q}$ is modeled by a an explicit step-up transformer of $0.3 \mathrm{pu}$. The power flow data of the WFs are presented in Table I. The control mode for the wind turbines are set to $P$-priority, where the active power is kept to its reference value although a larger reactive power is required to keep the grid voltage constant to the reference value. Despite the control mode, all converter parameters are adapted to still allow the WFs to generate the required amount of reactive power from the present grid codes.

The WF parameter values are dependent on the design values of the grid codes and can computed using Eq. (3) and (4). The dimensioning requirement of $V_{c, \max }$ occurs when the grid voltage is the highest and the maximum requirement of generated/absorbed reactive power exists.

1) Grid Code 1: The dimensioning requirements occur in the upper right corner of the depicted grid code in Fig. 3, with a power factor of $\cos \theta_{R}=0.91$ and with $V_{g, \max }=1.05$. Using this value for $\theta_{R}$ and assuming $f_{\max }=1.01$, values of $V_{c, \max }=1.21$ and $I_{c, \max }=1.22$ can be computed. 


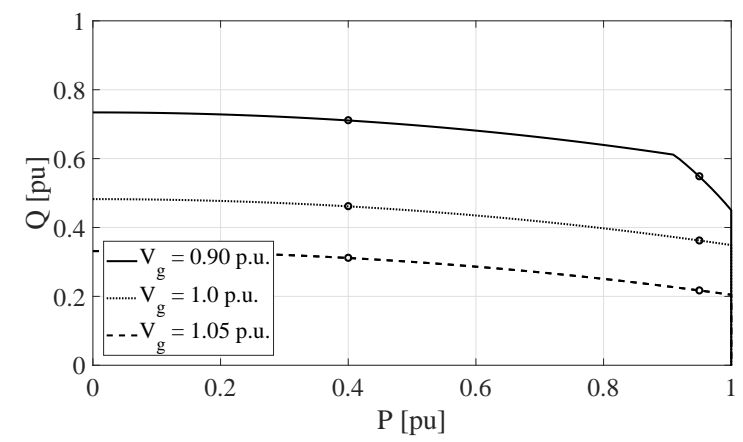

Fig. 4. PQ-capacity diagram under Grid Code 2

TABLE II

DESIGN VALUES FOR GRID CODE 2

\begin{tabular}{lllll}
\hline & $V_{g, \max }$ & $\cos \theta_{R}$ & $V_{c, \max }$ & $I_{c, \max }$ \\
\hline Corner 1 & 0.9 & 0.91 & 1.11 & $\mathbf{1 . 2 2}$ \\
Corner 2 & 1.0 & 0.96 & 1.13 & 1.16 \\
Corner 3 & 1.05 & 0.98 & $\mathbf{1 . 1 4}$ & 1.13 \\
\hline
\end{tabular}

2) Grid Code 2: The dimensioning requirements can occur in either of the right hand corners of the depicted grid code in Fig. 3. Compared with Grid Code 1 , both $V_{g, \max }$ and $\theta_{R}$ vary in this case, causing $V_{c, \max }$ and $I_{c, \max }$ to vary as well. The three requirements by each corner are evaluated in Table II. The PQ-capacity diagram is found in Fig. (4) with operating points for $40 \%$ and $95 \%$ of maximum $\mathrm{P}$ marked out. The largest values of $V_{c, \max }$ and $I_{c, \max }$ is then dimensioning for the converter. As a comparison, Grid Code 2 allows a smaller dimensioning $V_{g, \max }$ compared to Grid Code 1, while the $I_{c, \max }$ requirement is constant.

3) Grid Code 3: The design values are calculated in a similar manner as for Grid Code 1, resulting in $V_{c, \max }=1.09$ and $I_{c, \max }=1.12$. The parameters for all grid codes are then incorporated into the dynamic models of the WFs.

\section{Simulation RESUlts}

The results for the different simulations cases are presented Table III, in which all design aspects are varied: grid codes (type 1 - 3), WF output (High wind and Low wind), and control scheme $\left(V_{\text {cntrl }}\right.$ and $\left.V_{\text {reserv }}\right)$. The increase in load in $\%$ compared to the base case is represented by $\Delta P_{L, \text { all }}$. The last state that the system meets the defined stability criterion is presented as the result in the table.

1) Impact of grid code design: The different grid codes was found to have a small effect on the stability of the analyzed system. For instance, Grid Code 1 (with the strictest requirements) only increased the $\Delta P_{L, \text { all }}$ by $0.2 \%$ respectively $0.4 \%$ for case type A and B, compared to Grid Code 3 (with the least strict requirements). However, the relatively small stability improvement should be put into relation to the, compared to the whole grid, relatively small increase in reactive power capacity of the WFs.

In Fig. 5, the generated reactive power and 1 voltage for case 1,2 , and 9 are presented for the same level of increased load (7.9\%), each representing a different grid code. The reactive power output of case 1 and 2 are identical, since neither the current nor the voltage limitation is met. The generated reactive power for case 9 is reduced and the voltage collapses, mainly due to a lower $I_{c, \max }$-value and higher converter currents due to lower grid voltages. Although the larger $I_{c, \text { max }}$-values only improved the voltage stability marginally in the simulated cases, the actual benefit of more reactive power is highly dependent on other factors such as the level of penetration from wind power in a power system. Since voltage instability in general is correlated to low grid voltages, overdimensioning $V_{c, \max }$ to allow more reactive power output at high grid voltages could be argued to be an inefficient measure to increase stability. Instead, a more adaptive scheme, as for Grid Code 2, would be preferred.

2) Impact of wind power output: The most significant impact on the LTVS was the placement of the largest WF, WF6. Not surprisingly, by placing more generation in the "Central" area, closer to the larger load centers, it resulted in a significant enhancement of the stability. However, the impact is highly affected by the output of the WFs and the increase was found to be reduced during occasions of low wind.

Another aspect to consider is that WFs do not always generate full active power, both due to wake effects and wind speed variations. In these cases, the WF has increased possibilities to support the grid with reactive power, even without reducing the active power. In power systems with large penetration of wind power, the system is likely most sensitive to disturbances during occasions of low wind if the active power needs to be transmitted long distances from other areas to compensate the loss of generation. Thus, the ability of a FC-WF to support the grid with reactive power is also highest when the need for reactive power is high.

3) Impact of proposed voltage control scheme: The functionality of the proposed control scheme $V_{\text {reserv }}$ is illustrated in Fig. 6 for a stable version of Case 5A. In the figure, the reactive power is controlled to zero as long as the grid voltage is above 0.95 p.u. As the grid voltage decreases below 0.95 , the WF initiates its reactive power output to stabilize the voltage.

The different control strategies had some impact on the stability of the system and lower levels $\Delta P_{L, \text { all }}$ were possible with the proposed control scheme. Again, the impact was lower during both occasions of low wind, and when WF6 was located in the "North" area. Although the proposed control scheme in most cases would not be optimal, the results indicate that it could be utilized during certain conditions. For instance, if a larger WF would be located in an area with low requirements of reactive power, it could be an option to reduce the wear of converter IGBTs to both extend the life-time of the devices and to reduce the need for maintenance. However, this would require that grid codes can be adaptable to allow different requirements on FC-WFs depending on, for instance, the placement of the WF or specific need at the grid cite.

\section{CONCLUSION}

This paper analyzes the impacts on long-term voltage stability from different integration aspects of FC-WFs, such as grid codes and reactive power control. The paper has tested 
TABLE III

SimUlations RESUlTS WiTH WF6 LOCATED IN CENTRAL REgION

\begin{tabular}{|c|c|c|c|c|c|c|c|c|c|c|}
\hline WF6 located in "Central" area & Case $1 \mathrm{~A}$ & Case $2 \mathrm{~A}$ & Case $3 \mathrm{~A}$ & Case $4 \mathrm{~A}$ & Case $5 \mathrm{~A}$ & Case 6A & Case 7A & Case $8 \mathrm{~A}$ & Case 9A & Case $10 \mathrm{~A}$ \\
\hline Grid Code & 1 & 2 & 1 & 2 & 1 & 2 & 1 & 2 & 3 & 3 \\
\hline WF Output & High & High & Low & Low & High & High & Low & Low & High & Low \\
\hline Control Scheme & $\mathrm{V}_{\text {ctrld }}$ & $\mathrm{V}_{\text {ctrld }}$ & $\mathrm{V}_{\text {ctrld }}$ & $\mathrm{V}_{\text {ctrld }}$ & $\mathrm{V}_{\text {reserv }}$ & $\mathrm{V}_{\text {reserv }}$ & $\mathrm{V}_{\text {reserv }}$ & $\mathrm{V}_{\text {reserv }}$ & $\mathrm{V}_{\text {ctrld }}$ & $\mathrm{V}_{\text {ctrld }}$ \\
\hline $\begin{array}{l}\Delta P_{L, \text { all }} \text { before stability criterion } \\
\text { violation (\% to base case) }\end{array}$ & $8.0 \%$ & $8.0 \%$ & $1.9 \%$ & $1.9 \%$ & $7.1 \%$ & $7.1 \%$ & $1.7 \%$ & $1.7 \%$ & $7.8 \%$ & $1.8 \%$ \\
\hline WF6 located in "North" area & Case 1B & Case 2B & Case 3B & Case 4B & Case 5B & Case 6B & Case 7B & Case 8B & Case 9B & Case 10B \\
\hline Grid Code & 1 & 2 & 1 & 2 & 1 & 2 & 1 & 2 & 3 & 3 \\
\hline WF Output & High & High & Low & Low & High & High & Low & Low & High & Low \\
\hline Control Scheme & $\mathrm{V}_{\text {ctrld }}$ & $\mathrm{V}_{\text {ctrld }}$ & $\mathrm{V}_{\text {ctrld }}$ & $\mathrm{V}_{\text {ctrld }}$ & $\mathrm{V}_{\text {reserv }}$ & $\mathrm{V}_{\text {reserv }}$ & $\mathrm{V}_{\text {reserv }}$ & $\mathrm{V}_{\text {reserv }}$ & $\mathrm{V}_{\text {ctrld }}$ & $\mathrm{V}_{\text {ctrld }}$ \\
\hline $\begin{array}{l}\Delta P_{L, \text { all }} \text { before stability criterion } \\
\text { violation ( } \% \text { to base case) }\end{array}$ & $5.0 \%$ & $5.0 \%$ & $1.3 \%$ & $1.3 \%$ & $3.9 \%$ & $3.9 \%$ & $1.2 \%$ & $1.2 \%$ & $4.6 \%$ & $1.3 \%$ \\
\hline
\end{tabular}
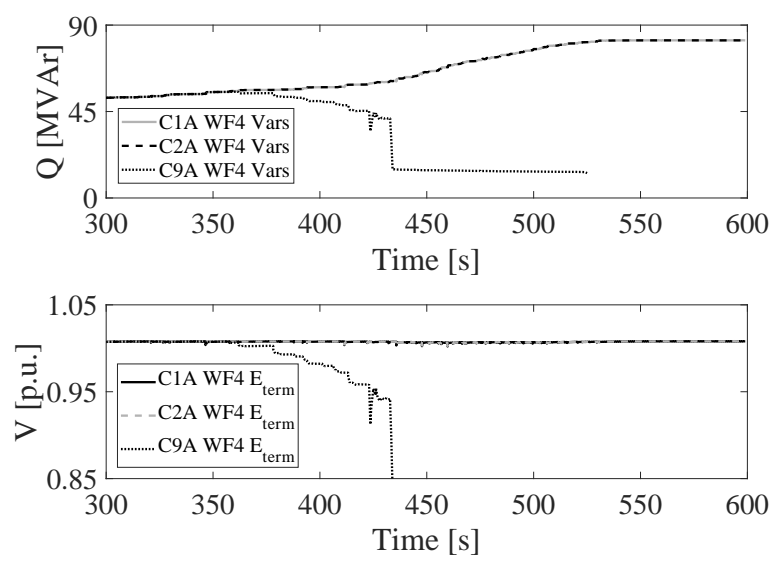

Fig. 5. Generated reactive power and terminal voltage for WF4. Difference illustrated between simulation cases 1,2 , and 9 .
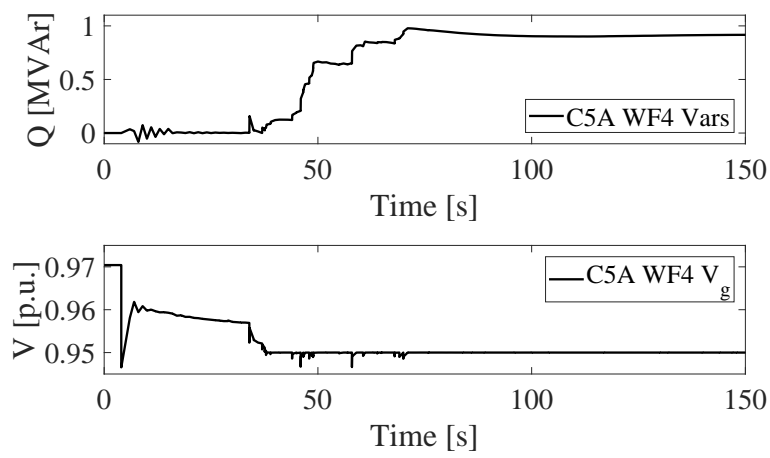

Fig. 6. Generated reactive power and grid voltage $\left(V_{g}\right)$ for WF4, case 5A

different cases and shows, for instance, that over-dimensioning of a FC-WF does not in all cases increase the stability. If such over-dimensioning is implemented, it is mainly the $I_{c, \text { max }^{-}}$ ratings of the converters that should be increased since the voltage limitation of the converters seldom are reached during voltage instability events. A restrictive reactive control scheme is also tested, and although it is found to reduce the stability in some cases, it could be used during certain conditions to reduce maintenance and wear of components. Moreover, the placement of larger WFs is found to have the largest impact on the LTVS of a power system, and the closer larger WFs are located to load centers, the more they contribute to the system stability. Thus, if ancillary services would take into account the actual improvement that the FC-WFs is providing, such aspects should be included in the design of those.

\section{ACKNOWLEDGMENT}

The work presented in this paper has been financially supported by Energimyndigheten (Swedish Energy Agency) and Svenska kraftnät (Swedish National Grid) within the SamspEL program.

\section{REFERENCES}

[1] "Global wind report," Global Wind Energy Council, Tech. Rep., 2017.

[2] R. R. Londero, C. d. M. Affonso, and J. P. A. Vieira, "Long-term voltage stability analysis of variable speed wind generators," IEEE Trans. Power Syst., vol. 30, no. 1, pp. 439-447, Jan 2015.

[3] "Establishing a network code on requirements for grid connection of generators," Commission Regulations (EU) 2016/631, European Union, Apr. 2016.

[4] "The grid code," National Grid Electricity Transmission, Mar. 2017.

[5] N. R. Ullah, K. Bhattacharya, and T. Thiringer, "Wind farms as reactive power ancillary service providers-technical and economic issues," IEEE Trans. Energy Convers., vol. 24, no. 3, pp. 661-672, Sept 2009.

[6] R. Billinton et al., "Adequacy assessment considerations in wind integrated power systems," IEEE Trans. Power Syst., vol. 27, no. 4, pp. 2297-2305, Nov 2012.

[7] E. Vittal, M. O’Malley, and A. Keane, "A steady-state voltage stability analysis of power systems with high penetrations of wind," IEEE Trans. Power Syst., vol. 25, no. 1, pp. 433-442, Feb 2010.

[8] M. Chinchilla, S. Arnaltes, and J. C. Burgos, "Control of permanentmagnet generators applied to variable-speed wind-energy systems connected to the grid," IEEE Trans. Energy Convers., vol. 21, no. 1, pp. 130-135, March 2006.

[9] J. V. de Vyver et al., "Comparison of wind turbine power control strategies to provide power reserves," in 2016 IEEE Int. Energy Conf. (ENERGYCON), April 2016, pp. 1-6.

[10] M. Triggianese, F. Liccardo, and P. Marino, "Ancillary services performed by distributed generation in grid integration," in 2007 Int. Conf. Clean Elect. Power, May 2007, pp. 164-170.

[11] T. Van Cutsem et al., "Test systems for voltage stability analysis and security assessment," IEEE/PES Task Force, Tech. Rep. PESTR19, Aug. 2015. [Online]. Available: http://resourcecenter.ieeepes.org/pes/product/technical-publications/PESTR19

[12] PSS®E 34.2.0 Program Application Guide: Volume II, Siemens Power Technologies International, Schenectady, NY, Apr. 2017.

[13] K. Ma et al., "Thermal loading and lifetime estimation for power device considering mission profiles in wind power converter," IEEE Trans. on Power Elect., vol. 30, no. 2, pp. 590-602, Feb 2015.

[14] D. Zhou et al., "Reliability and energy loss in full-scale wind power converter considering grid codes and wind classes," in 2014 IEEE Energy Conversion Congress and Exposition (ECCE), Sept 2014, pp. 3067-3074. 